atmospheric conditions on the summit of Mount Hamilton.

Aluminium is a difficult metal to sputter by cathode disintegration, and the most effective method of depositing the aluminium films has been found to be by an evaporation process in a high vacuum of the order of $0.0001 \mathrm{~mm}$. of mercury. The aluminium is heated in small tungsten coils arranged opposite the mirror to be coated; the aluminium evaporates and condenses on the face of the mirror. The low pressure enables each atom of aluminium, after evaporation, to travel in a straight path to the mirror with small probability of collision with other atoms. In coating the mirror of the Crossley reflector, twelve helical tungsten coils were arranged round a 36-inch circle at a distance of 18 inches from the mirror. Each coil had 10 turns and to each turn a U-shaped aluminium wire, $\frac{3}{8}$ inch long and $\frac{1}{32}$ inch diameter, was clamped. Each coil was connected in turn to the electrical supply, at a voltage of 20 volts, the entire process of distilling from the twelve coils requiring about three minutes. The mirror was placed on brass bars fastened to a reinforced steel bedplate, one inch in thickness ; this arrangement enabled gases underneath the mirror to be pumped out easily. The bell-jar covering the mirror was of $\frac{1}{4}$-inch sheet steel, stiffened at the bottom by a rolled angle iron, and machined to give a perfect plane surface. A lead fuse wire was pressed into a circular groove in the bedplate, at the bottom of the bell-jar ; the angle iron was bolted down by 24 bolts exerting a force of 50 tons on the fuse wire gasket, to which atmospheric pressure on exhausting added another 10 tons.

The mirror surface must be absolutely clean for a satisfactory coat. The most satisfactory way of securing the requisite cleanliness with a large mirror was by removing foreign material with an electric discharge from a central electrode. With the arrangements used for the Crossley mirror a very uniform thickness (about $\frac{1}{1} \delta \mu$ ) of coat was obtained.

Dr. Strong finds that it is possible to coat speculum metal gratings with aluminium; the reflectivity is increased about 50 per cent for visible light and by an even greater extent in the ultra-violet. The higher orders of spectrum also become relatively brighter. The definition was found not to be impaired by the coating. The coat can be dissolved by caustic potash, which does not attack the speculum metal. This application of the process should prove of value in the laboratory as well as in astronomical spectroscopy.

It is hoped that apparatus for aluminising telescope mirrors up to a size of 36 inches diameter will be available in Great Britain before long. Some experimental work has been in progress, and a piece of plate-glass coated with aluminium was on view at the meeting of the Royal Astronomical Society on March 9.

\title{
The Lyochromes: a New Group of Animal Pigments
}

\section{By Phictpr Elunnger and Walter Koschara, Düsseldorf}

$\mathrm{I}^{\mathrm{N}}$ the observations of living animal organs by the 'intravital microscope'1 it was noticed that cells of some organs of the animal not previously treated with fluorescent dyestuffs contained substances which were excited by ultra-violet light to give a characteristic yellow-green fluorescence. Such substances were chiefly found in the liver cells and in the epithelial cells of the first convoluted tubules of the kidney of all the animals examined, including horses, oxen, dogs, cats, rabbits, guinea pigs, rats, mice, frogs, etc. In the liver two other groups of cells could be found which were fluorescent, but far less strongly; the Kuppfer star-cells, shining with a dull orangeyellow fluorescence, and single cells, showing a reddish fluorescence, near to the blood vessels. The two groups last named have no connexion with the pigments with which this article deals. The intensity of the fluorescence of the epithelial cells of the kidney, and also of the liver cells, appeared to be diminished when the animals (rats) were fed on a diet free from nitrogen, and to be augmented after the administration of urea. The suggestion arose that these pigments might have some connexion with the formation or the excretion of urea, because they were found in great quantity just at the sites of the intensive formation and excretion, and therefore of great concentration, of urea. Since it appeared likely that these pigments had great physiological importance, we tried to isolate and identify them.

Animal pigments have been for a long time an object of interest to physiologists and chemists. Especially by the researches of chemists, knowledge of them has been greatly increased during recent decades. The animal pigments hitherto known are nearly all soluble in neutral organic solvents under suitable conditions, and this property was highly important for their isolation and recognition. Only a few of the animal pigments previously known are strongly fluorescent, and their fluorescence differs in colour from that of the pigments now found in the kidney and the liver.

The first attempts at extraction showed that our pigments were completely insoluble in the usual indifferent solvents, such as ether, chloroform, benzol, ligroin, and that, on the other hand, they were soluble in water. As a guide in our attempts at isolation we used the characteristic yellow-green fluorescence, which clearly revealed even extremely small quantities, and which was further characterised by the fact that it was to a high degree dependent on the $p \mathrm{H}$, being changed reversibly to a violet fluorescence by both acids 
and alkalis. Further, the fluorescence was destroyed by light. The solutions of our pigments are coloured orange-yellow in stronger, vellow in weaker concentrations. The pigments are resistant to acids, but they are destroyed by hot alkalis.

After having determined the solubility of the pigments in water we proceeded, in the first instance, to mince organs fresh from the slaughterhouse (livers and kidneys of horses and oxen) or the same organs from recently killed dogs, in which we had determined the presence of the pigments by intravital microscopy, and, after mincing, we extracted such materials with water. The watery extract was freed from albumen, sugar and other contaminating substances and concentrated. It appeared from these attempts that the yield of raw pigments from both organs was very small. We searched therefore for another source of these pigments, promising a better yield, and found it in whey. We convinced ourselves by tests that the pigments of whey correspond to those of the kidney and the liver, in respect of their fluorescence and their reactions to acid, alkali and light. Having found pigments with these properties in many different materials in our first researches, we concluded that we were dealing with a new group of substances of wide distribution, and we named them 'Lyochromes'.

The pigments of whey have been described recently by Bleyer and Callmann ${ }^{2}$ and by Gerngross and Schulz's . From the work of Bleyer and Callmann the difficulty of isolating such substances is evident. Bleyer and Callmann could, indeed, greatly concentrate these substances, but they were unable to isolate them. They came to the conclusion that the pigment of whey belongs to the oxyproteinic acids; a conclusion which, as we shall see later, cannot be maintained. Whey first became useful as a raw material, when we had found the right adsorbents for concentrating and isolating the pigments. Fuller's earth was found to be the best adsorbent, and the adsorption was most successful from a slightly acid solution, such as that natural to whey, which always has an acid reaction due to lactic acid.

From the adsorption on fuller's earth, which was washed several times with water and alcohol, the pigments were eluted by mixtures of pyridine and water. In this manner we obtained concentrates of pigments, which were purified by precipitation of contaminating substances, and which could be induced to crystallise from watery solution.

We were able to isolate five crystalline coloured substances, which we described as 'Lactoflavins $a-e^{s_{5}}$, and which differ from one another in constitution, crystalline form, solubility and intensity of the colour in solution. It is possible, perhaps even likely, that the chromogen component in all these pigments is identical. By careful removal of impurities we obtained at first three crystalline pigments, lactoflavins $a, b$ and $c$, which are dis. tinguished by slight solubility in water and in mixtures of concentrated acetic acid and acetone from the other lactoflavins, $d$ and $e$. They differ from one another in crystalline form, basicity and percentage composition as follows :-Lactoflavin $b$ (small hexagonal tablets; $\mathrm{C} 3.5 \cdot 7 ; \mathrm{H} 3 \cdot 3 ; \mathrm{N}$ $32 \cdot 0$ ), and lactoflavin $c$ (needles of the form of a dragon-fly's wings ; $\mathrm{C} 35.7 ; \mathrm{H} 2.6 ; \mathrm{N} 31.3$ ) have a similar composition. On the other hand, lactoflavin $a$ (crystals in nodular aggregates; $C$ ' 33.5 ; H 4.0 ; $N 21.6$ ), differs from the other two, especially by its lower content of nitrogen. Lactoflavins $b$ and $c$ have a percentage composition close to that of uric acid (C $35 \cdot 7 ; \mathrm{H} 2 \cdot 4 ; N^{3} 3 \cdot 3$ ), but differ from uric acid in their greater solubility in water, and in the property of not being precipitated by ammonium chloride. Lactoflavins $a, b$ and $c$ have no melting-points. The crystals are coloured orange-red. They dissolve in water to give orangecoloured solutions, yellow when more dilute. The solutions have a yellow-green fluorescence. It was not possible to fix the molecular weights. The watery solutions lose their colour by heating with alkali, with evolution of ammonia. The three pigments give the murexide test.

From 100 litres of whey we obtain, in the most favourable case, perhaps $10 \mathrm{mgm}$. of each of the three pure lactoflavins $a, b$ and $c$. Much loss is caused by the purification of the crude crystals, a procedure in which one must avoid temperatures above $60^{\circ}$. For it was evident that on heating the watery solutions of these lactoflavins a decomposition occurred. This decomposition yields a colourless substance, very difficult to dissolve in water, of a purin-character, and a pigment which remains in the solution, and which shows all the qualities of the Lyochromes. The pigment produced by this cleavage, which we call lactoflavin $d$, has been isolated by us from the mother-liquors of the lactoflavins $a-c$, as a pigment very much more soluble in water than the Lyochromes hitherto described. It is not strictly proved, as yet, that this pigment from the mother-liquors is identical with that formed by the decomposition of the slightly soluble Purin-Lyochromes.

Lactoflavin $d$ crystallises in the form of reddish. yellow needles, which melt at $270^{\circ}-273^{\circ}$ with complete decomposition. 'The data per cent given by analysis (C 52.69; $\mathrm{H} 5.84 ; \mathrm{N} 14.38$ ) indicate the formula $\mathrm{C}_{16} \mathrm{H}_{20} \mathrm{O}_{8} \mathrm{~N}_{4}$, or $\mathrm{C}_{17} \mathrm{H}_{20} \mathrm{O}_{7} \mathrm{~N}_{4}$. The reddishyellow watery solution of lactoflavin $d$ fades, on heating, with alkali. t $\Omega$ a pale yollow ssloux, withsut. appreciable evolution of ammonia. The murexide test gives a negative result with this pigment.

In isolating lactoflavin $d$ we have found a further crystalline pigment, which is precipitated in microscopic aggregates and which is called lactoflavin $e$. Its solubility in water and its content of nitrogen ( 24 per cent) give it a position between the lactoflavins $a-c$, on one hand, and lactoflavin $d$ on the other. The lactoflavin $e$ gives a positive murexide reaction, but only with chlorate and hydrochloric acid ('forced murexide test').

By a procedure corresponding to that of Warburg and Christian", which will be quoted later, a 
decomposition product can be obtained from the Lyochromes of whey by irradiation of their alkaline solutions, which differs from the Lyochromes by its solubility in chloroform. This substance crystallises in the form of reddish-yellow, small, woolly needles; it melts with decomposition at $315^{\circ}-317^{\circ}$. It is slightly soluble in hot water, also in ammonia, and is easily soluble in dilute sodium hydroxide. The solutions are fluorescent in the same way as the Lyochrome solutions. The results of analysis of this product of photochemical decomposition (C 61.97 ; H $5.19 ; \mathrm{N} 20.58$ per cent) indicate the formula $\mathrm{C}_{14} \mathrm{H}_{14} \mathrm{O}_{2} \mathrm{~N}_{4}$. Its properties make it likely that it is, at least, very nearly connected, perhaps identical, with the substance formed by light from the Iyochromes of yeast, obtained by Warburg and Christian. If we accept for lactoflavin $d$ the formula $\mathrm{C}_{17} \mathrm{H}_{20} \mathrm{O}_{2} \mathrm{~N}_{4}$, and we compare it with the formula of the photochemical cleavage product of lactoflavin $d$, a difference of $\mathrm{C}_{3} \mathrm{H}_{6} \mathrm{O}_{5}$ is found.

In the transformation of lactoflavin $d$ by light we must probably reckon with a reaction proceeding in several steps. At first $\mathrm{H}_{2} \mathrm{O}$ will be split off, and then a further substance free from nitrogen, and finally a transformation of the nitrogencontaining, coloured molecule will take place. On this assumption, one may divide the difference between the formulæ of lactoflavin $d$ and the photochemical cleavage-product, $\mathrm{C}_{3} \mathrm{H}_{6} \mathrm{O}_{5}$, into $\mathrm{H}_{2} \mathrm{O}$ (water) and $\mathrm{C}_{3} \mathrm{H}_{4} \mathrm{O}_{4}$ (malonic acid?). Not only the higher melting point of the cleavage product, but also its behaviour to oxidation with chromic acid, indicate that its molecule is more stable than the molecule of lactoflavin $d$. While by oxidation with chromic acid, 8 mols of carbonic acid are formed from lactoflavin $d$ in about one hour and a half, when the reaction comes to an end, by the same treatment of the cleavage product only about two mols of carbonic acid are evolved in the course of six hours, without the formation of carbonic acid being completed. In contrast to the lactoflavin $d$, we can extract with ether, from the oxidation products of the pigments soluble in chloroform, a substance which corresponds completely to the Lyochromes with respect to its colour and fluorescence, but in which nitrogen can no longer be demonstrated by the test of Lassaigne. The search for the constitution of the Lyochromes must start with such decomposition products.

An important property of the Lyochromes, which must be expressed in the constitutional formulæ, is the reversible reduction to a leuco-substance. These leuco-substances are formed, for example, by a biological process if whey is left standing for some time, so that it becomes covered with a film of microbes. The liquid under this film does not show the Lyochrome fluorescence, but the fluores. cence can be restored immediately by shaking it with air. Chemically the leuco-substances can be obtained by reduction with hydrosulphite, with hydrogen sulphide in a weakly alkaline solution, and also with titanous chloride. Of other chemical properties of the Lyochromes, in the first place their great stability to oxidising agents must be mentioned. The Lyochromes are not attacked by concentrated nitric acid, bromine water or hydrogen peroxide. Hydrogen peroxide in presence of iron salts and cold permanganate attacks them only slowly, but they are very quickly destroyed by hot permanganate.

Hitherto the existence of Lyochromes has been determined by ourselves in animal organs, in whey and in urine. The wide distribution of this new group of natural pigments is further evident from the papers of Warburg and Christian and also of Kuhn, Györgyi and Wagner-Jauregg?. These investigators detected yellow-green fluorescent pigments of Lyochrome character in yeast in very high concentration, in cultures of the lactic acid bacterium, in muscle, in white of egg, and also in vegetable materials. Warburg and Christian found, in the course of their search for the so-called second respiratory ferment, pigments of Lyochrome character, and they were able to show that the combination of a yellow-green fluorescent pigment with a carrier of high molecular weight represents this iron-free respiratory ferment itself. This respiratory ferment is, therefore, not dialysable, in contrast to the Lyochromes of whey. We have found that, in contrast to that of cow's milk, the pigment of human milk is also fixed on a carrier, probably on albumin. Lastly, Kuhn, Györgyi and Wagner-Jauregg have been led to this new sphere of pigment investigation by researches directed to the isolation of the vitamin $\mathbf{B}_{2}$. Vitamin $\mathbf{B}_{2}$ appears to belong to the Lyochromes. To this statement we must make the reservation that the crystallised Lyochromes which, in the opinion of these investigators, are the cause of the vitamin effect, require, for the production of their effect on growth, to be supplemented by a substance chemically not yet defined (vitamin $\mathbf{B}_{4}$ ). The crystallised pigments, which Kuhn, Györgyi and Wagner-Jauregg were able to isolate first from white of egg, and then from whey, are similar or identical with the lactoflavin $d$ isolated by ourselves from whey. The possibility cannot be denied that the different natural Lyochromes may consist of the same pigment component united with different other substances, acting as carriers.

We find accordingly, in whey, Lyochromes of very different molecular dimensions. Including the substances obtained by decomposition of the original Lyochromes, we can at present construct the following series, arranged in order of molecular dimensions :

(1) The pigments united to a non-dialysable carrier (albumin?), from human milk, corresponding to the second respiratory ferment of Warburg and Christian.

(2) The pigments in combination with purin. substances (lactoflavins $a-c$ ).

(3) A single pigment (lactoflavin d) corresponding to the ovoflavin and the lactoflavin of Kuhn, Györgyi and Wagner-Jauregg.

(4) The photochemical cleavage product, that 
is, the pigment without $\mathrm{H}_{2} \mathrm{O}$ (water) and $\mathrm{C}_{3} \mathrm{H}_{4} \mathrm{O}_{4}$ (malonic acid?), corresponding to the cleavage product from yeast of Warburg and Christian.

(5) The oxidation product of the photochemical cleavage product, soluble in ether (free from nitrogen?).

Warburg and Christian have described the evolution of urea from their photochemical cleavage product by treatment with alkali, by which means the remaining substance, $\mathrm{C}_{9} \mathrm{H}_{10} \mathrm{O}_{2} \mathrm{~N}_{2}$, loses its whole power of fluorescence and all but a small remnant of its colour. It must be accepted that in this treatment an intramolecular transformation of the remaining substance also takes place; for our probably nitrogen-free oxidation product, obtained from the product of photochemical cleavage, still possesses fluorescence and colour to such an extent that the nitrogen content is very unlikely to have any connexion with these properties.

The three starting-points of the researches leading to the discovery of the new group of animal pigments-namely, the functions of the liver and the kidney, the respiratory ferment, and the action of vitamin $B_{2}-$ together indicate the great physiological importance of this new class of pigments. While the function of the Lyochromes as respiratory ferment is completely explained, their character as vitamin $B_{2}$ still requires further in. vestigation, since in the researches so far made their effect as vitamin $B_{2}$ was evident only with the addition of chemically unknown substances. The physiological significance of the occurrence of Lyochrome in the kidney and the liver is still quite unknown. On the respiration of normal tissue cells Lyochromes have no effect, as we ourselves, and also Wagner-Jauregg and Ruska ${ }^{8}$, have observed. On the other hand, Stern and Greville ${ }^{9}$ found that mammalian red blood corpuscles, which have practically no intrinsic respiratory activity, show a significant increase of oxidation in the presence of Lyochrome. It is very probable, how ever, that the substances used in these experiments as Lyochromes were not of that character; for, according to the investigations of one of us on the Lyochromes of the urine, the Urochrome used by Stern and Greville for their respiration experiments has no Lyochrome properties.

To summarise: The Lyochromes are characterised by the following qualities: (1) solubility in water ; (2) red to orange colour of the crystals, and orange to yellow colour of their watery solutions ; (3) yellow-green fluorescence; (4) extinction of this fluorescence by acid and alkaline reactions; (5) reversible reduction to leuco-substances; stability against oxidising agents.

The chemical investigation of the group, in spite of the small concentration of the Lyochromes in organic materials, has already advanced so far that in the near future we may expect that their chemical structure will be revealed, and that a knowledge of new relations between chemical constitution and physiological action will be afforded thereby.

'The method of 'intravital microscopy' has been described by Ph. Ellinger and A. Hirt in the Zeitschrift für Anatomie und Ent wicklungsgeschichte, vol. 90, p. 791, 1929, and in "Abderhalden Handbuch der biologischen Arbeitsmethoden", vol. 5, II , p. 1753 1930. It permits living animal organs to be examined with the strongest microscopical magnifications by injecting the animal with fluorescent dyestuffs. With ultra-violet illumination these dyes provide, by fluorescence in the cells themselves, the light required for visible illumination of the microscopical picture.

${ }_{2}$ Bleyer and Callmann, Biochem. Z., 155, $54 ; 1925$.

${ }^{3} \mathrm{O}$. Gerngross and M. Schulz, Milchwirtschaftliche Forschung, 6, $567 ; 1928$.

Details of this procedure as well as of further chemical operations are described in our publications: Ph. Ellinger and W. Koschara, Berichte der Deutschen Chemischen Gesellschaft, 66, 315, 808, 1411 ; 1933

Wage had made an agreement with $\mathbf{R}$. Kuhn, P. Györgyi and Th. Wagner-Jauregg, who worked over the same field and who called their substances 'Flavins', to call the whole group 'Lyochromes' and their single specimens 'Flavins', with the addition of the names of the materials of origin, so that the Flavin from milk is called 'Lactolavin'.

Warburg and Christian, Biochem. Z., 257, 492 ; 1933.

${ }^{7}$ R. Kuhn, P. Györgyi and Th-Wagner-Jauregg, Ber. Deutschen Chem. G'esell., 68, 317, 576, 1034, 1577; 1933.

${ }^{8}$ Th. Wagner-Jauregg and H. Ruska, Ber. Deutschen Chem. Gesell., 66, 1298; 1933.

• K. G. Stern and G. D. Greville, Naturwissenschaften, 22, 720 ; 1933.

\section{Obituary}

\section{Prof. F. LL. Griffith}

$\mathrm{F}^{\mathrm{R}}$ RANCIS LLEWELLYN GRIFFITH, whose death at the age of seventy-one years occurred on March 14, was, like a number of other distinguished Englishmen, the son of a clergyman, the Rev. John Griffith, who was for many years rector of Sandridge, Herts, and a mathematician of some repute. After being educated at Brighton College, Sedbergh and Highgate, he came up to Oxford as a scholar of Queen's College, where, under the influence of Prof. A. H. Sayce, he began those studies which were destined to win him later a world-wide fame. He took his B.A. degree in 1884, and during the winter seasons of that and the three following years he was engaged in excavation and other research work in Egypt under the leadership of Petrie and Naville. For some months of the season $1886-87$ he was busy copying the inscriptions in the tombs of the First Intermediate Period and Middle Kingdom at Asyût and Dêr Rîfeh. His publication of these texts ("The Inscriptions of Asyût and Dêr Rîfeh", 1889) not only shows that even at this early date he had acquired a sound knowledge of Middle Egyptian, but already displays that scholarliness and meticulous accuracy which are so characteristic of all his subsequent work.

From 1888 until 1896, Griffith was an assistant in the Department of British and Mediæval Antiquities in the British Museum. In 1892 he was made assistant professor of Egyptology at University College, London, a post which he retained until he was appointed reader of Egyptology at Oxford in 1901. During those years his output was remarkable both for quantity and quality, its crowning achievement being the 